\title{
Synthesis of tunable plasmonic metal-ceramic nanocomposite thin films by temporally modulated sputtered fluxes
}

Daniel Magnfält, E. Melander, Robert Boyd, V. Kapaklis and Kostas Sarakinos

The self-archived version of this journal article is available at Linköping University Electronic Press:

http:/ / urn.kb.se/ resolve?urn=urn:nbn:se:liu:diva-137839

N.B.: When citing this work, cite the original publication.

Magnfält, D., Melander, E., Boyd, R., Kapaklis, V., Sarakinos, K., (2017), Synthesis of tunable

plasmonic metal-ceramic nanocomposite thin films by temporally modulated sputtered fluxes, J ournal of Applied Physics, 121(17),. https:// dx.doi.org/ 10.1063/ 1.4979139

Original publication available at:

https:// dx.doi.org/ 10.1063/ 1.4979139

Copyright: AIP Publishing

http:/ / www.aip.org/ 


\title{
Synthesis of tunable plasmonic metal-ceramic
} nanocomposite thin films by temporally modulated

\section{sputtered fluxes}

D. Magnfält ${ }^{1}$, E. Melander ${ }^{2}$, R.D. Boyd ${ }^{3}$, V. Kapaklis$^{2}$, and K. Sarakinos ${ }^{1, *}$

${ }^{1}$ Nanoscale Engineering Division, Department of Physics, Chemistry and Biology (IFM), Linköping University, SE-58183 Linköping, Sweden

2Department of Physics and Astronomy, Uppsala University, Box 516, SE-751 20

Uppsala, Sweden

${ }^{3}$ Plasma and Coatings Physics Division, Department of Physics, Chemistry and Biology (IFM), Linköping University, SE-58183 Linköping Sweden

*Author to whom correspondence should be addressed (E-mail address: kostas.sarakinos@liu.se)

\begin{abstract}
The scientific and technological interest for metal-dielectric nanocomposite thin films emanates from the excitation of localized surface plasmon resonances (LSPRs) on the metal component. The overall optical response of the nanocomposite is governed by the refractive index of the dielectric matrix and the properties of the metallic nanoparticles in terms of their bulk optical properties, size and shape and the inter-particle distance of separation. In order to tune film morphology and optical properties, complex synthesis
\end{abstract}


processes which include multiple steps-i.e., film deposition followed by post-deposition treatment by thermal or laser annealing-are commonly employed. In the present study, we demonstrate that the absorption resonances of $\mathrm{Ag} / \mathrm{AlO} \times \mathrm{N}_{\mathrm{y}}$ nanocomposite films can be effectively tuned from green $(\sim 2.4 \mathrm{eV})$ to violet $(\sim 2.8 \mathrm{eV})$ using a single-step synthesis process that is based on modulating the arrival pattern of film forming species with submonolayer resolution, while keeping the amount of $\mathrm{Ag}$ in the films constant. Our data indicate that the optical response of the films is the result of LSPRs on isolated Ag nanoparticles that are seemingly shifted by dipolar interactions between neighboring particles. The synthesis strategy presented may be of relevance for enabling integration of plasmonic nanocomposite films on thermally sensitive substrates.

\section{INTRODUCTION}

Nanocomposites consisting of noble metal nanoparticles in a dielectric matrix have attracted a large amount of interest due to their optical properties, which arise from the excitation of localized surface plasmon resonances (LSPRs) on the metal particles ${ }^{1}$. The LSPR gives rise to a strong absorption around the resonance energy ${ }^{1}$ and can lead to an intense coloration of the materia| ${ }^{2}$. It also results in a strong localized enhancement of the electric field around the nanoparticles making these materials interesting for a number of applications, such as sensors ${ }^{3}$, absorbers ${ }^{4-6}$, substrates for surface enhanced Raman scattering $^{7}$, optically active materials ${ }^{8,9}$ and materials exhibiting an enhanced magnetooptical coupling ${ }^{10}$. The energy position and width of the absorption, as well as the

plasmonic properties in such a nanocomposite, depend on the dispersion of the electromagnetic radiation in the dielectric matrix in combination with the bulk optical 
properties of the metal nanoparticle, the nanoparticle size and shape, and the inter-particle separation $^{11,12}$.

Metal-dielectric nanocomposites are commonly synthesized in the form of thin films using atom-by-atom vapor deposition in which thermodynamics, kinetics, and temporal profile of the deposition flux can be used to manipulate film growth and control film microstructure and morphology ${ }^{13-21}$. For instance, when the noble metal and dielectric material film forming species are deposited simultaneously, the low mutual solubility leads to precipitation of randomly dispersed metal nanoparticles with a relatively broad size distribution ${ }^{22,23}$. If instead, the vapor species forming the noble metal and dielectric matrix are deposited in an alternating fashion, a self-organized microstructure is formed which is characterized by its out-of-plane periodicity, while individual 3D island layers are weakly correlated with each other $r^{9,16,24-29}$. By changing the process conditions (e.g., growth temperature and temporal profile of the deposition fluxes) the size of 3D islands and the distance between 3D island layers can be varied to tune out-of-plane and in-plane separation between the metal nanoparticles. This route has been used to grow metaldielectric nanocomposite films and control their optical properties. ${ }^{9,14,25,30-32}$ However, in order to fine-tune the plasmonic response and fully exploit the potential of metal-ceramic nanocomposite films, multiple-step synthesis processes in which film deposition followed by post-deposition treatment by thermal or laser annealing are commonly employed ${ }^{19,} 23$, 33-37. Besides the associated technical complexity, these processes are not compatible with e.g., thermally sensitive (e.g., organic) substrates limiting the application reach of plasmonics film within the realm hard inorganic materials. In the present study, we demonstrate a single-step synthesis process that allows to tune the plasmonic response 
of $\mathrm{Ag} / \mathrm{AlO} \times \mathrm{N} \mathrm{N}_{\mathrm{y}}$ nanocomposite thin films with high precision. This is achieved by employing a recently developed thin film synthesis route termed Modulated Impulse Magnetron Sputtering Interplay (MIMSI) ${ }^{38}$. This approach generates vapor fluxes that are modulated with sub-monolayer resolution thereby facilitating control of atomic arrangement over multiple length scales ${ }^{38,39}$ which in the present case allows for controlling microstructure in a way that the optical absorption resonance of the nanocomposites is effectively tuned from green $(\sim 2.4 \mathrm{eV})$ to violet $(\sim 2.8 \mathrm{eV})$, while maintaining a constant $\mathrm{Ag}$ content in the film. In a wider perspective our study highlights the feasibility of strategies that entail controlling nanoscale atomic structure to create complex materials with e.g., tunable magneto-optical response for sensing applications and thereby expand relevance of these nanocomposites for plasmonics-based applications.

\section{EXPERIMENTAL DETAILS}

\section{A. Thin film synthesis}

The MIMSI synthesis route is technically implemented using multiple power supplies to generate well-defined trains of electrical pulses and thereby sequentially activate spatially separated magnetron sources. Each single pulse in a pulse train has a width of the order of a few tens of microseconds and generates vapor that corresponds to $10^{-4}$ to $10^{-2}$ monolayers (ML). Hence, the arrival pattern of film forming species can be modulated with sub-monolayer resolution and precision by changing the number of pulses supplied in each pulse train, while pulse width, frequency and amplitude can be tuned to control kinetic conditions during growth in an independent fashion ${ }^{38,39}$. The MIMSI method was used in the present study to grow $\mathrm{Ag} / \mathrm{AlO} \times \mathrm{N}_{\mathrm{y}}$ nanocomposite films simultaneously onto 10x10x0.5 $\mathrm{mm}^{3}$ pieces of $\mathrm{Si}(100)$ with a $\sim 500 \mathrm{~nm}$ thick thermally grown $\mathrm{SiO}_{2}$ layer and 
D263 glass substrates. Depositions were performed in an ultra-high vacuum vessel with a base pressure of $\sim 10^{-7} \mathrm{~Pa}$. Vapor was generated by two spatially separated magnetron sputtering sources equipped with $\mathrm{Al}$ and $\mathrm{Ag}$ targets with a $75 \mathrm{~mm}$ diameter and $6 \mathrm{~mm}$ thickness (purity: $99.99 \%$ ). The sputtering sources were mounted at a 40 degree angle with respect to the surface normal. The targets were sputtered reactively in $\mathrm{Ar}-\mathrm{O}_{2}-\mathrm{N}_{2}$ mixtures with flows of $47.5,0.7$, and $1.2 \mathrm{sccm}$, respectively, resulting in a total working pressure of $0.67 \mathrm{~Pa}$. No intentional heating was applied during deposition, the target to substrate distance was $125 \mathrm{~mm}$ to minimize radiative heating of the substrates from the cathodes, and the substrates were continuously rotated at a speed of $10 \mathrm{rpm}$. The Ag and Al cathodes were supplied with time averaged electrical power of 30 and $265 \mathrm{~W}$, respectively, in the form of pulse trains with a width of $50 \mu \mathrm{s}$ and a frequency of $100 \mathrm{~Hz}$ (Ag cathode) and $1000 \mathrm{~Hz}$ (Al cathode). At these conditions $\mathrm{Ag}$ and $\mathrm{AlO}_{\mathrm{x}} \mathrm{N}_{\mathrm{y}}$ were found to grow with a rate of $0.0185 \mathrm{nms}^{-1}\left(\sim 8 \times 10^{-4} \mathrm{ML} / \mathrm{pulse}\right)$ and $0.1112 \mathrm{nms}^{-1}\left(\sim 5 \times 10^{-4}\right.$ $\mathrm{ML} /$ pulse), respectively. For the remainder of the article, we choose to express the amount of $\mathrm{Ag}$ and $\mathrm{AlO}_{\mathrm{x}} \mathrm{N}_{\mathrm{y}}$ film forming species deposited per pulse train and thereby quantify the modulation profile of the deposition flux in $\mathrm{nm}$. For all $\mathrm{Ag} / \mathrm{AlO} \times \mathrm{N}_{\mathrm{y}}$ films, see illustration in Fig. 1, a $10 \mathrm{~nm}$ thick $A l O_{x} N_{y}$ buffer was first deposited, onto which a $A g-A I O \times N_{y}$ stack was grown followed by another $10 \mathrm{~nm}$ thick $\mathrm{AlO} \times \mathrm{N}_{\mathrm{y}}$ capping layer to protect the $\mathrm{Ag}-\mathrm{AlO} \times \mathrm{N}_{\mathrm{y}}$ stack from ambient exposure during ex situ characterization. Various stacks were synthesized by sequentially supplying pulse trains to the $\mathrm{Ag}$ and $\mathrm{Al}$ cathodes and repeating this for five times. Each pulse train generated $1 \mathrm{~nm}$ of $\mathrm{Ag}$ vapor, while the amount of $\mathrm{AlO}_{\mathrm{x}} \mathrm{N}_{\mathrm{y}}$ vapor ranged from 1 to $8 \mathrm{~nm}$ which was controlled by tuning the length of the pulse train (i.e., number of pulses) applied to the Al cathode. The Ag vapor flux magnitude and Ag cathode pulsing frequency were chosen to facilitate film growth in the 
so-called coalescence-controlled growth regime ${ }^{40,41}$. Concurrently, the amount of $\mathrm{AlO} \times \mathrm{N}_{\mathrm{y}}$ film forming species deposited in the stack was varied in the range described above so as to tune the out-of-plane separation and interaction between Ag islands.

\section{B. Microstructural characterization}

The crystalline structure of the film stacks was investigated by grazing incidence $\mathrm{X}$-ray diffractometry (GIXRD) in a four-circle diffractometer (Panalytical) equipped with a parallel beam mirror with a $0.5^{\circ}$ divergence slit, a parallel plate collimator and an area detector operated in open detector mode. The incidence angle $(\omega)$ was $2^{\circ}$, the scan range $30^{\circ}-80^{\circ}$ with a step size of $0.04^{\circ}$. X-ray reflectometry (XRR) was used to determine the thickness of the individual layers. In addition to the XRR, X-ray diffuse scattering (XDS) experiments were performed for all samples exhibiting Bragg peaks by recording rocking curves ( $\omega$ scans) at $2 \theta$ angles corresponding to the first Bragg peak of the reflectogram. The XRR and XDS measurements were performed with the same diffractometer configuration used for the GIXRD investigation with the exception of the use of a $0.25^{\circ}$ divergence slit and an

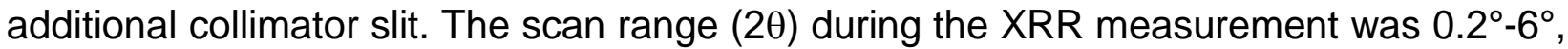
while the scan range $(\omega)$ during the XDS measurement was $3^{\circ}$. In both cases the step size was $0.01^{\circ}$. The reflectometry data were simulated using the GenX software ${ }^{42}$ using a model consisting of a substrate, a buffer layer, the $\mathrm{Ag}-\mathrm{AlO} \times \mathrm{N}_{\mathrm{y}}$ stack and the cap layer. To reduce the number of free parameters during the simulation/fitting the densities of all $A l O \times N_{y}$ layers were assumed to be the same, the same assumption was also made for the Ag layers. The thicknesses, surface roughness and interdiffusion of respective layers in the $\mathrm{Ag}-\mathrm{AlO} \times \mathrm{N} \mathrm{N}_{\mathrm{y}}$ stack were also coupled for the same reason. 
Based on the results obtained from the X-ray analysis, $\mathrm{Ag} / \mathrm{AlO} \times \mathrm{N}_{\mathrm{y}}$ films were selected for electron microscopy investigations in order to obtain information about the size and separation of the $\mathrm{Ag}$ domains and the structure of the $\mathrm{AlO}_{\mathrm{x}} \mathrm{N}_{\mathrm{y}}$ matrix. Scanning transmission electron microscopy combined with high angle annular dark field imaging (HAADF-STEM) was chosen as the preferred analytical route. Images produced by HAADF-STEM are dominated by mass contrast, assuming that the sample has consistent thickness. Therefore the Ag particles can be clearly distinguished from the $\mathrm{AlO}_{x} \mathrm{~N}_{\mathrm{y}}$ matrix. Prior to analysis, cross sectional samples were thinned to electron transparency by mechanical polishing followed by argon ion milling at a shallow incidence angle $\left(4^{\circ}\right)$. All images were taken with a Technai G2 (FEI) microscope operated in STEM mode and fitted with a HAADF detector.

\section{Optical characterization}

The plasmonic properties of the $\mathrm{Ag} / \mathrm{AlO} \times \mathrm{N}_{\mathrm{y}}$ films were determined by optical transmittance measurements, on samples grown on glass substrates. Measurements were performed for a fixed angle of incidence of $0.5^{\circ}$ from the surface normal in the range of 1.1 to $3.2 \mathrm{eV}$ using a supercontinuum laser (Fianium Whitelase UV-enhanced). This light source provides a resolution of 0.01 and $0.03 \mathrm{eV}$ in the higher and lower end of the measured energy range. The collected transmittance data were fitted using a $3^{\text {rd }}$ order polynomial to determine the resonance position. Transmittance measurements were complemented by spectroscopic ellipsometry (SE). Ellipsometric data were acquired in reflection mode at angles of incidence $45^{\circ}-75^{\circ}$ in $5^{\circ}$ steps from samples deposited on $\mathrm{SiO}_{2} / \mathrm{Si}$ substrates for the energy range 0.7-3.0 eV using a dual rotating compensator ellipsometer (RC2, J. A. 
Woollam Inc.). The data were fitted to a three-phase model consisting of substrate, film and vacuum. The substrate was modeled by a $1 \mathrm{~mm}$ Si slab with a top layer of $\mathrm{SiO}_{2}$, the thickness of which was determined by measuring the optical response of the substrate prior to deposition. Reference data for the substrate layers were taken from Herzinger et al. ${ }^{43}$. The films consisted of three layers, i.e., a $10 \mathrm{~nm}$ thick $\mathrm{AlO}_{\mathrm{x}} \mathrm{N}_{\mathrm{y}}$ buffer layer, a $\mathrm{Ag}$ AlO $\times N_{y}$ layer of varying thickness, depending on the deposition conditions, and a $10 \mathrm{~nm}$ $A l O x N_{y}$ cap layer. The $A l O x N_{y}$ layers were modeled as Cauchy layers with an Urbach absorption tail with the parameters fitted to ellipsometry data acquired from a single $\mathrm{AlO}_{\mathrm{x}} \mathrm{N}_{\mathrm{y}}$ film grown under identical deposition conditions as the buffer and cap layers. The isolated $\mathrm{Ag}$ particles making up the $\mathrm{Ag}$ rich layers in the $\mathrm{Ag}-\mathrm{AlO} \times \mathrm{N}_{\mathrm{y}}$ stack support LSPRs. Hence, the dielectric function, $\tilde{\epsilon}(\omega)$ of the $\mathrm{Ag}-\mathrm{AlO} \times \mathrm{N}_{\mathrm{y}}$ layers was described by the Lorentz model,

$$
\tilde{\epsilon}(\omega)=\epsilon_{\infty}+\sum_{j=1}^{m} \frac{f_{j} \omega_{o j}^{2}}{\omega_{o j}^{2}-\omega^{2}-i \gamma_{j} \omega}(1) .
$$

In Eq. (1), $\epsilon_{\infty}$ is a background constant that accounts for inter-band transitions at high energies (outside the experimental spectral range) not described by the oscillators. Each oscillator $(j)$ is centered at a resonance frequency $\omega_{0 j}$ with strength and damping factors $f_{j}$ and $\gamma_{j}$, respectively. All Ag-AlO $\times \mathrm{N}_{\mathrm{y}}$ layers could be adequately described by a single Lorentz term, except the sample with $1 \mathrm{~nm} \mathrm{AlO} \times \mathrm{N}_{\mathrm{y}}$ in the $\mathrm{Ag}-\mathrm{AlO}{ }_{\mathrm{x}} \mathrm{N}_{\mathrm{y}}$ stack where a second oscillator had to be employed to fit the experimental data.

\section{RESULTS AND DISCUSSION}

XRR data, presented in Fig. 2 (a), show that the samples have a layered structure as manifested by the existence of Bragg peaks (indicated with arrows in Fig. 2 (a)) with the 
exception of the $1 \mathrm{~nm} \mathrm{AlO}_{\mathrm{x}} \mathrm{N}_{\mathrm{y}}$ sample. In addition, it is seen that the Bragg peaks shift to higher angles as the amount of vapor deposited per $\mathrm{AlO}_{x} \mathrm{~N}_{\mathrm{y}}$ pulse train decreases which is consistent with the formation of thinner spacer layers between the Ag island layers. This is accompanied by an increase in the width of the Bragg peaks indicating a deterioration of the layer structure. Moreover, weak Kiessig fringes, corresponding to the total film thickness, are also visible for the samples grown by depositing 2, 4, 5, 7, and $8 \mathrm{~nm}$ of $\mathrm{AlO} \times \mathrm{N}_{\mathrm{y}}$. The presumable nanocomposite structure with $\mathrm{Ag}$ particles in an $\mathrm{AlO} \times \mathrm{N}_{\mathrm{y}}$ matrix makes accurate modeling of the reflectometry data difficult, hence focus was to obtain the best possible agreement between model and data for the critical angle and Bragg peak positions. This was possible for the data recorded from the samples with 4, 5, 7 and $8 \mathrm{~nm}$ of $\mathrm{AlO}_{\mathrm{x}} \mathrm{N}_{\mathrm{y}}$ in the stack layer, while somewhat inferior agreement was obtained for the data from samples with 1 and $2 \mathrm{~nm}$ of $\mathrm{AlO}_{\mathrm{x}} \mathrm{N}_{\mathrm{y}}$ as shown by the solid lines in Fig. 2 (a). The model parameters resulting the best fitting are listed in Table I. There it is seen that the Ag thickness is larger than the nominal value of $1 \mathrm{~nm}$ for all samples which indicated that $\mathrm{Ag}$ grows in a 3D fashion on the $\mathrm{AlO}_{x} \mathrm{~N}_{\mathrm{y}}$ layers. However, deviations in the reported thickness values are observed which may be attributed to roughness in the Ag layers and intermixing between $\mathrm{Ag}$ and $\mathrm{AlO} \times \mathrm{N}_{\mathrm{y}}$ layers which complicates the fitting procedure. $\mathrm{XDS}$ data are presented in Fig. 2 (b). The intense narrow central peak corresponds to specular reflection off the sample while the shoulders of varying width result from diffuse scattering. The samples with $\mathrm{AlO}_{x} \mathrm{~N}_{\mathrm{y}} 2,4$ and $5 \mathrm{~nm}$ in the stack exhibit characteristic Yoneda wings ${ }^{44}$ at angles corresponding to the critical angle of total internal reflection. Integrating and comparing the intensity of the specularly and diffusely scattered intensity, gives an indication of how the roughness changes as a function of the $\mathrm{AlO}_{x} \mathrm{~N}_{\mathrm{y}}$ layer thickness. The 
data (inset in Fig. 2 (b)) shows that the film roughness decreases as the amount of $\mathrm{AlO}_{x} \mathrm{~N}_{\mathrm{y}}$ deposited per pulse train increases.

The microstructure of samples with 1, 2, and $5 \mathrm{~nm} \mathrm{AlO} \times \mathrm{N}_{\mathrm{y}}$ in the $\mathrm{Ag}-\mathrm{AlO} \times \mathrm{N}_{\mathrm{y}}$ stack was also investigated by cross-section HAADF-STEM (Fig. 3). All micrographs show the expected structure of the films described in section II and in Fig. 1 i.e., the buffer $A l O \times N_{y}$ layer followed by the $\mathrm{Ag}-\mathrm{AlO} \times \mathrm{N}$ s stack. In order to minimize the contribution of overlapping Ag particles to the STEM micrographs, wedge shaped specimens prepared by ion milling at a shallow angle $\left(4^{\circ}\right)$ were imaged. Whilst this lead to very thin regions, the height of these thin regions is smaller than the film thickness and thereby the capping layer and some of the $\mathrm{Ag}$ particles have been removed. Comparisons between the thin regions shown in Fig. 3 and thicker regions of the specimens, see supplementary material ${ }^{45}$, indicate that the out-of-plane particle separation and the particle morphology remains consistent and is not modified by the ion milling procedure. A general feature observed in all micrographs is that the stack layer consists of particles in a matrix. The particles appear brighter than the matrix, i.e., they most likely consist of $\mathrm{Ag}$ that is the largest atomic number element in the immiscible $\mathrm{Ag} / \mathrm{AlO} \times \mathrm{N}_{\mathrm{y}}$ system giving rise to the highest HAADF intensity ${ }^{46}$. The presence of crystalline $\mathrm{Ag}$ is confirmed by GI-XRD data, see supplementary material ${ }^{45}$, that reveal a broad and weak feature at an angle of approximately 38 degrees corresponding to the $\mathrm{Ag}(111)$ reflection $\left(2 \theta=38.1^{\circ}\right)^{47}$ in an otherwise featureless diffraction pattern. All in all, the data presented above confirm that the stacks in our films consist of crystalline $\mathrm{Ag}$ in an amorphous $\mathrm{AlO} \times \mathrm{N}_{\mathrm{y}}$ matrix. Due to overlap between particles, values for size and the in- and out-of-plane particle separation could only be extracted for the sample grown by depositing $5 \mathrm{~nm}$ of $A l \mathrm{O}_{x} \mathrm{~N}_{\mathrm{y}}$ per pulse 
train. We therefore discuss this sample quantitatively and compare it in a qualitative fashion with the 1 and $2 \mathrm{~nm} \mathrm{AlO} \times N_{y}$ samples. For the $2 \mathrm{~nm} \mathrm{AlO} \times N_{y}$ sample (Fig. 3(b)) the particle size and shape appears similar to that of the $5 \mathrm{~nm} \mathrm{AlO} \times N_{y}$ sample (Fig. 3(c)) but the film exhibits a less pronounced layer structure with overlaps between neighboring particles for both the in- and out-of-plane directions. In the case of the $1 \mathrm{~nm} A l \mathrm{O}_{x} \mathrm{~N}_{\mathrm{y}}$ sample (Fig. 3(a)), the particle sizes appear larger compared to the other two samples while the layered structure has broken down and particles overlap extensively. For the sample with $5 \mathrm{~nm}$ AlOxNy the Ag particles appear to be slightly elongated in nature with dimension $4.6 \mathrm{~nm}$ in-plane, $3.6 \mathrm{~nm}$ out-of-plane and a particle separation of $\sim 6 \mathrm{~nm}$ with an estimated measurement error of $\sim 0.3 \mathrm{~nm}$. These values are in good agreement with the results obtained by XRR (Table I) when taking the considerable layer roughness into account. Moreover, weak ordering on the nearest neighbor island level can be evidenced in the TEM data for the sample with $5 \mathrm{~nm} \mathrm{AlO} \times N_{y}$ in the stack (Fig 3(c)), which is in agreement with data reported in the literature for a number of metal-dielectric nanocomposite systems ${ }^{16,28,48,49}$.

The effect of growth conditions on the film microstructure as observed in the XRR and TEM data (Figs. 2 and 3, respectively) can be understood by the way that the modulation of the flux (i.e., the amount of $\mathrm{Ag}$ and $\mathrm{AlO} \times \mathrm{N}_{\mathrm{y}}$ deposited per respective pulse train) affects the processes at the film growth front as suggested in the following. The first step for setting the microstructure of the $\mathrm{Ag}-\mathrm{AlO} \times \mathrm{N}_{\mathrm{y}}$ nanocomposite, is the nucleation and formation of $3 \mathrm{D} \mathrm{Ag}$ islands on the $\mathrm{AlO}_{\times} \mathrm{N}_{\mathrm{y}}$ surface owing to the larger surface energy of noble metals (e.g., Ag) as compared to that of polar insulators (e.g., $\left.\mathrm{AlO}_{\times} \mathrm{N}_{\mathrm{y}}\right)^{50}$. As more vapor is deposited, islands grow in size, impinge on each other, and the coalescence 
process commences. The relatively low pulsing frequency used for Ag deposition in this study allows coalescence between small $\mathrm{Ag}$ islands to complete, resulting in larger equiaxed islands ${ }^{40,41,51}$. Moreover, this process can lead to a weak quasi-hexagonal ordering of the growing islands ${ }^{52}$. Ag deposition is followed by $\mathrm{AlO}_{x} \mathrm{~N}_{\mathrm{y}}$ vapor arrival on the growing surface which, due to kinetic limitations and the lower surface energy, caps the $\mathrm{Ag}$ islands and follows the corrugation induced by these islands. Newly deposited $\mathrm{Ag}$ adatoms form atomic islands preferentially in the troughs of the corrugated $\mathrm{AlO}_{x} \mathrm{~N}_{\mathrm{y}}$ surface; this is due to curvature driven Ag adatom diffusion from the positive curvatures at the peaks to the troughs exhibiting negative curvature ${ }^{53}$. This process is repeated for every Ag layer in the multilayer resulting in the quasi-ordered structure of the first layer being inherited throughout the stack. Based on the structure forming pathway described above, it stands to reason that Ag island arrays characterized by out-of-plane periodicity and weak in plane-ordering cannot be formed when the amount of $\mathrm{AlO}_{\mathrm{x}} \mathrm{N}_{\mathrm{y}}$ vapor deposited is too small for the $\mathrm{AlO}_{x} \mathrm{~N}_{\mathrm{y}}$ layer to completely cap $\mathrm{Ag}$ islands, and thus for two successive Ag island layers to be correlated, as observed for the samples with 1 and 2 $n m \mathrm{AlO}_{x} \mathrm{~N}_{\mathrm{y}}$ in the stack (Figs. 3 (a) and (b), respectively). An incomplete $\mathrm{AlO}_{x} \mathrm{~N}_{\mathrm{y}}$ layer would also mean that $\mathrm{Ag}$ islands remain exposed to subsequent pulse train of $\mathrm{Ag}$ vapor, which may be the reason for the larger particles observed in Fig. 3 (a) as compared to the remaining micrographs in Fig. 3.

The optical properties of the different $\mathrm{Ag} / \mathrm{AlO} \times \mathrm{N}_{\mathrm{y}}$ samples can be assessed by the data in Fig. 4 which presents results of transmission measurements performed at near normal incidence $\left(0.5^{\circ}\right)$. All spectra exhibit a broadband absorption feature (manifested as transmission minimum) that can be attributed to the LSPRs excited on the Ag particles. In 
addition, the position of this feature shifts consistently from $\sim 2.76$ to $2.43 \mathrm{eV}$ as the amount of $\mathrm{AlO} \times \mathrm{N}_{\mathrm{y}}$ vapor deposited per pulse train in the stack layer decreases from 8 to $2 \mathrm{~nm}$. This redshift may be attributed to the increase in dipolar interaction between Ag particles in adjacent island layers as their distance decreases; an effect that has been theoretically described for isolated particles and it is utilized in plasmonic rulers for accurate determination of nanoscale distances ${ }^{54}$, 55. Besides inter-particle interactions, unintentional changes in density and composition—and by extension in the refractive index-of the dielectric matrix among the various samples, as well as changes in the particles shape, may also explain the observed changes in the films optical response. An exception with respect to the trends described above is the $1 \mathrm{~nm} \mathrm{AlO} \times N_{y}$ sample, the transmission spectrum of which also exhibits a wide absorption feature (i.e., significantly lower transmission with respect to the other samples) extending from $\sim 1$ to $\sim 2 \mathrm{eV}$, while the primary resonance position is located at $\sim 2.61 \mathrm{eV}$ as compared to $\sim 2.43 \mathrm{eV}$ for the 2 $\mathrm{nm} \mathrm{AlO} \times \mathrm{N}_{\mathrm{y}}$ sample. The appearance of a second plasmonic resonance frequency (as in the case of the $1 \mathrm{~nm} \mathrm{AlO} \times N_{y}$ sample in the present study) has been reported in the literature, for metal thin films close to the percolation threshold, and has been attributed to exceptionally strong dipole interaction triggered by the close proximity of metal atomic islands ${ }^{56}$. However, changes in the particles shape and size as the $\mathrm{AlO}_{\times} \mathrm{N}_{\mathrm{y}}$ layer becomes thinner and does not fully cover Ag, may also explain the observed trends in the optical properties in accordance with earlier reported data on model plasmonic systems ${ }^{2}$. The transmission measurements were complemented by variable-angle spectroscopic ellipsometry. Typical examples of the ellipsometric angles, $\Psi$ and $\Delta$, for an incidence angle of $60^{\circ}$, together with best fits using the model described in section II, for the samples with 
1, 2, 5 and $8 \mathrm{~nm} \mathrm{AlO} \mathrm{N}_{\mathrm{y}}$ layers are presented in Figs. 5 (a) and (b). The real, $\varepsilon_{1}(\omega)$, and imaginary, $\varepsilon_{2}(\omega)$, parts of the complex dielectric function of the Lorentz oscillator layers, used to describe the stack $\mathrm{Ag}-\mathrm{AlO} \times \mathrm{N}_{\mathrm{y}}$ layer, are shown in Fig. 5 (c) and (d), respectively for samples with $1,2,5$ and $8 \mathrm{~nm}$ of $A l \mathrm{O}_{x} \mathrm{~N}_{\mathrm{y}}$. The resonance frequencies of the Lorentz oscillators (as represented by the positions of the maxima of $\varepsilon_{2}(\omega)$ in Fig. 5 (d)) are in reasonable agreement with, and follow the same trend as the absorption maxima obtained from the transmission measurements, as seen in Fig. 6. Moreover, $\varepsilon_{2}(\omega)$ exhibit broad features, in line with the optical transmission data, and can be attributed to broadening caused by the rather broad particle size distribution in combination with scattering of the conduction electrons in the Ag particles due to the small particle size.

\section{SUMMARY AND OUTLOOK}

In this work, we presented a single-step process for synthesizing $A g / A l O_{x} N_{y}$ nanocomposite thin films with plasmonic response effectively tuned from green $(\sim 2.4 \mathrm{eV})$ to violet $(\sim 2.8 \mathrm{eV})$. This was achieved by using a recently developed thin film deposition route termed MIMSI to generate multi-atomic vapor fluxes with their arrival pattern modulated with sub-monolayer resolution and thereby control the microstructure of Ag$\mathrm{AlO}_{x} \mathrm{~N}_{\mathrm{y}}$ stacks while maintaining a constant $\mathrm{Ag}$ content. Microstructural characterization showed that nanocomposite films consisting of crystalline $\mathrm{Ag}$ island layers in an amorphous $\mathrm{AlO}_{x} \mathrm{~N}_{\mathrm{y}}$ matrix were obtained. The out-of-plane distance between Ag particles was controlled by changing the $\mathrm{AlO}_{\times} \mathrm{N}_{\mathrm{y}}$ layer thickness. Optical transmission and spectroscopic ellipsometry measurements revealed that the optical response of the nanocomposite films is defined by LSPRs on the Ag nanoparticles that are shifted by (i) 
the emerging dipolar interactions between neighboring $\mathrm{Ag}$ island layers and/or (ii) unintentional drift in the composition and density of the dielectric matrix among the various samples. The synthesis strategy presented herein could facilitate deposition of tunable plasmonic films on thermally sensitive substrates since it does not entail any postdeposition annealing step. It could also enable the design of materials with tailor-made magneto-optical response by substituting Ag with a magnetic metal and thereby expand the reach of plasmonic-based applications ${ }^{57}$.

\section{SUPPLEMENTARY MATERIAL}

The supplemental material file presents grazing incidence X-ray diffractometry data for all $\mathrm{Ag} / \mathrm{AlO} \mathrm{N}_{\mathrm{y}}$ films. The diffraction data exhibit weak $\mathrm{Ag}(111)$ reflections in an otherwise featureless pattern supporting the conclusion that our films are nanocomposites consisting of crystalline $\mathrm{Ag}$ in an amorphous $\mathrm{AlO}_{\mathrm{x}} \mathrm{N}_{\mathrm{y}}$ matrix. The file also present large area HAADF-STEM overview from the data presented in Fig. 3 which shows that a similar structure is retained across the samples.

\section{ACKNOWLEDGEMENTS}

KS should like to acknowledge Linköping University for financial support through the "LiU Research Fellows Program, 2011-2015" and the "LiU Career Contract (Dnr-LiU-201501510), 2015-2020". VK should like to acknowledge the Knut and Alice Wallenberg foundation for financial support under project number 2015.0060. DM and KS wish to acknowledge Mr. Bo Lü (Linköping University) for helpful discussions.

\section{REFERENCES}


U. Kressig and M. Wollmer, Optical Properties of Metal Clusters (Springer-Verlag, Berlin Heidelberg, 1995).

A. Tao, P. Sinsermsuksakul, and P. Yang, Nat. Nanotechnol. 2, 435 (2007).

N. M. Figueiredo, T. Kubart, J. A. Sanchez-García, R. Escobar Galindo, A.

Climent-Font, and A. Cavaleiro, J. Appl. Phys. 115, 63512 (2014).

S. Dutta-gupta, O. J. F. Martin, S. D. Gupta, and G. S. Agarwal, Opt. Express 20, 4764 (2012).

N. Zhang, K. Liu, H. Song, Z. Liu, D. Ji, X. Zeng, S. Jiang, and Q. Gan, Appl. Phys. Lett. 104, 203112 (2014).

S. Esposito, A. Antonaia, M. L. Addonizio, and S. Aprea, Thin Solid Films 517, 6000 (2009).

S. Nie, Science 275, 1102 (1997).

R. Del Coso, J. Requejo-Isidro, J. Solis, J. Gonzalo, and C. N. Afonso, J. Appl. Phys. 95, 2755 (2004).

J. Toudert, H. Fernandez, D. Babonneau, S. Camelio, T. Girardeau, and J. Solis, Nanotechnology 20, 475705 (2009).

J. Menéndez, B. Bescós, G. Armelles, R. Serna, J. Gonzalo, R. Doole, A. PetfordLong, and M. Alonso, Phys. Rev. B 65, 205413 (2002).

1 K. L. Kelly, E. Coronado, L. L. Zhao, and G. C. Schatz, J. Phys. Chem. B 107, 668 (2003).

2 C. Noguez, J. Phys. Chem. C 111, 3806 (2007).

13 R. Serna, C. N. Afonso, J. M. Ballesteros, A. Naudon, D. Babonneau, and A. K. Petford-Long, Appl. Surf. Sci. 138-139, 1 (1999).

4 S. K. Mandal, R. K. Roy, and A. K. Pal, J. Phys. D. Appl. Phys. 35, 2198 (2002). 
J.-P. Barnes, N. Beer, A. K. Petford-Long, A. Suárez-García, R. Serna, D. Hole, M. Weyland, and P. A. Midgley, Nanotechnology 16, 718 (2005).

D. Lantiat, J. Toudert, D. Babonneau, S. Camelio, C. Tromas, and L. Simonot, Rev. Adv. Mater. Sci. 15, 150 (2007).

G. Abrasonis, G. J. Kovács, L. Ryves, M. Krause, A. Mücklich, F. Munnik, T. W.

H. Oates, M. M. M. Bilek, and W. Möller, J. Appl. Phys. 105, 83518 (2009).

E. Ćspedes, J. Toudert, D. De Sousa Meneses, C. Prieto, and A. Traverse, J. Appl. Phys. 108, (2010).

A. Siozios, D. C. Koutsogeorgis, E. Lidorikis, G. P. Dimitrakopulos, T. Kehagias, H. Zoubos, P. Komninou, W. M. Cranton, C. Kosmidis, and P. Patsalas, Nano Lett. 12, 259 (2012).

N. M. Figueiredo, F. Vaz, L. Cunha, S. E. Rodil, and A. Cavaleiro, Surf. Coat. Technol. 255, 130 (2014).

M. Jerčinović, N. Radić, M. Buljan, J. Grenzer, I. Delač-Marion, M. Kralj, I. Bogdanović-Radović, R. Hübner, P. Dubček, K. Salamon, and S. Bernstorff, J. Nanoparticle Res. 16, 2296 (2014).

J. Xiong, M. Z. Ghori, B. Henkel, T. Strunskus, U. Schürmann, L. Kienle, and F. Faupel, Acta Mater. 74, 1 (2014).

A. Siozios, H. Zoubos, N. Pliatsikas, D. C. Koutsogeorgis, G. Vourlias, E. Pavlidou, W. Cranton, and P. Patsalas, Surf. Coat. Technol. 255, 28 (2014).

J. Gonzalo, R. Serna, J. . Requejo, J. Solís, C. . Afonso, and A. Naudon, Appl. Surf. Sci. 154-155, 449 (2000). Condens. Matter 15, S3001 (2003). 
D. Babonneau, G. Abadias, J. Toudert, T. Girardeau, E. Fonda, J. S. Micha, and F. Petroff, J. Phys. Condens. Matter 20, 35218 (2008).

E. Céspedes, D. Babonneau, O. Lyon, J. Sánchez-Marcos, S. Rouzière, C.

Prieto, L. Olivi, and A. Traverse, J. Appl. Phys. 107, 104306 (2010).

S. Bernstorff, V. Holý, J. Endres, V. Valeš, J. Sobota, Z. Siketić, I. Bogdanović-

Radović, M. Buljan, and G. Dražić, J. Appl. Crystallogr. 46, 1711 (2013).

M. Jerčinović, N. Radić, M. Buljan, J. Grenzer, I. Delač-Marion, M. Kralj, I.

Bogdanović-Radović, R. Hübner, P. Dubček, K. Salamon, and S. Bernstorff, J. Nanoparticle Res. 16, (2014).

J. C. G. de Sande, R. Serna, J. Gonzalo, C. N. Afonso, D. E. Hole, and A.

Naudon, J. Appl. Phys. 91, 1536 (2002).

31

R. Serna, A. Suárez-García, C. N. Afonso, and D. Babonneau, Nanotechnology 17, 4588 (2006).

E. Céspedes, D. Babonneau, D. De Sousa Meneses, C. Prieto, E. Fonda, O. Lyon, E. Briand, and A. Traverse, J. Appl. Phys. 109, (2011).

L. Yang, G. H. Li, L. D. Zhang, Appl. Phys. Lett. 76, 1537 (2000).

J. Sancho-Parramon, V. Janicki, M. Lončarić, H. Zorc, P. Dubček, S. Bernstorff, Appl. Phys. A. 103, 745 (2011).

V. Antad, L. Simonot, D. Babonneau, Nanotechnology, 24, 045606 (2013).

V. Antad, L. Simonot, D. Babonneau, J. Nanopart. Res. 16, 2328 (2014).

N. Kalfagiannis, A. Siozios, D.V. Bellas, D. Toliopoulos, L. Bowen, N. Pliatsikas, W.M. Cranton, C. Kosmidis, D.C. Koutsogeorgis, E. Lidorikis, and P. Patsalas, Nanoscale 8, 8236 (2016).

V. Elofsson, G. A. Almyras, B. Lü, R. D. Boyd, and K. Sarakinos, Acta Mater. 110, 
114 (2016).

K. Sarakinos and D. Magnfält, "Method of coating a substrate so as to provide a controlled in-plane compositional modulation", Patent pending application, PCT/EP2014/052831.

B. Lü, E. P. Münger, and K. Sarakinos, J. Appl. Phys. 117, 134304 (2015).

V. Elofsson, B. Lü, D. Magnfält, E. P. Münger, and K. Sarakinos, J. Appl. Phys. 116, 44302 (2014).

M. Björck and G. Andersson, J. Appl. Crystallogr. 40, 1174 (2007).

C. M. Herzinger, B. Johs, W. A. McGahan, J. A. Woollam, and W. Paulson, J. Appl. Phys. 83, 3323 (1998).

Y. Yoneda, Phys. Rev. 131, 2010 (1963).

See supplementary material at [URL will be inserted by publisher] for additional GIXRD and HAADF-STEM results.

6 O. L. Krivanek, M. F. Chisholm, V. Nicolosi, T. J. Pennycook, G. J. Corbin, N. Dellby, M. F. Murfitt, C. S. Own, Z. S. Szilagyi, M. P. Oxley, S. T. Pantelides, and S. J. Pennycook, Nature 464, 571 (2010).

ICDD powder diffraction file no. 00-004-0783.

M. Buljan, S. R. C. Pinto, A. G. Rolo, J. Martín-Sánchez, M. J. M. Gomes, J. Grenzer, A. Mücklich, S. Bernstorff, and V. Holý, Phys. Rev. B 82, 235407 (2010). M. Buljan, U. Desnica, M. Ivanda, N. Radić, P. Dubček, G. Dražić, K. Salamon, S. Bernstorff, and V. Holý, Phys. Rev. B 79, 35310 (2009).

C. T. Campbell, Surf. Sci. Rep. 27, 1 (1997).

B. Lü, V. Elofsson, E. P. Münger, and K. Sarakinos, Appl. Phys. Lett. 105, 163107 (2014). 
A. Steyer, P. Guenon, D. Beyens, and C. M. Knobler, Phys. Rev. B 42, 1086 (1990).

53

54 Chilkoti, ACS Nano 6, 9237 (2012).

56

57 1407 (2011).

W. W. Mullins, J. Appl. Phys. 28, 333 (1957).

N. Liu, M. Hentschel, T. Weiss, A. P. Alivisatos, and H. Giessen, Science. 332,

5 R. T. Hill, J. J. Mock, A. Hucknall, S. D. Wolter, N. M. Jokerst, D. R. Smith, and A.

T. W. H. Oates, and A. Mücklich, Nanotechnology 16, 2606 (2005).

G. Armelles, A. Cebollada, A. García-Martín, and M. U. González, Adv. Opt. Mater. 1, 10 (2013). 


\section{$\underline{\text { TABLES AND TABLE CAPTIONS }}$}

Table I. Microstructural characteristics of stack $\mathrm{Ag}-\mathrm{AlO} \times \mathrm{N} \mathrm{N}_{\mathrm{y}}$ layers as obtained from analysis of XRR measurements. Samples are designated by the amount of $\mathrm{AlO}_{x} \mathrm{~N}_{y}$ vapor deposited per pulse train, while in all cases the amount of Ag deposited per pulse train corresponds to $1 \mathrm{~nm}$.

\begin{tabular}{c|c|c|}
\begin{tabular}{c|c}
$A l O_{x} N_{y}$ \\
vapor per pulse train $[\mathrm{nm}]$
\end{tabular} & Ag thickness $[\mathrm{nm}]$ & AlO $\mathrm{N}_{\mathrm{y}}$ thickness $[\mathrm{nm}]$ \\
\hline 4 & 2.0 & 4.3 \\
5 & 1.3 & 5.9 \\
7 & 1.9 & 7.8 \\
8 & 2.1 & 9.1
\end{tabular}




\section{FIGURE CAPTIONS}

Fig. 1. Schematic illustration of the architecture of the $A g / A I O \times N_{y}$ sample consisting of the $A l O x N_{y}$ buffer layer, the $A g-A l O x N_{y}$ stack (5 bilayers) and the $A l O_{x} N_{y}$ capping layer. Note that the Ag layer in the $\mathrm{Ag}-\mathrm{AlO} \times \mathrm{N}$ y stack, albeit depicted as continuous layer, in reality agglomerates into Ag nanoparticles as explained in section II A.

Fig. 2. (a) XRR and (b) XDS data recorded from $A g / A I O_{x} N_{y}$ nanocomposite films for various amounts of $A l O_{x} N_{y}$ vapor deposited during growth of the $A g-A I O x N_{y}$ stack. The solid lines in (a) are generated by fitting the model parameters using the GenX software to the experimental data while the arrows mark the position of the first order Bragg reflections. The insert in (b) presents a plot of the specularly-to-total reflected x-ray intensity as a function of the amount of $\mathrm{AlO}_{\mathrm{x}} \mathrm{N}_{\mathrm{y}}$ deposited per pulse train length.

Fig. 3. HAADF-STEM images of $A g / A l O_{x} N_{y}$ nanocomposite films with 1,2 and $5 \mathrm{~nm}$ of AlOxNy (panel (a), (b) and (c), respectively) in the Ag-AlOxNy stack. (c) shows (main panel) the first three and (inset) the topmost silver layers from a nearby film region.

Fig. 4. Transmission spectra of $A g / A l O \times N_{y}$ nanocomposite films for various amounts of $\mathrm{AlO}_{\mathrm{x}} \mathrm{N}_{\mathrm{y}}$ deposited per pulse train in the stack layer. 
Fig. 5. (a) and (b) Typical spectroscopic ellipsometry spectra of $A g / A l O \times N y$ nanocomposite films and corresponding best fits to the three phase model described in section II C. (c) ) real, $\varepsilon_{1}(\omega)$, and (d) imaginary, $\varepsilon_{2}(\omega)$, parts of the complex dielectric corresponding to the Lorentz used to describe the stack $\mathrm{Ag}-\mathrm{AlO} \times \mathrm{N} \mathrm{N}_{\mathrm{y}}$ layer for the various samples.

Fig. 6. Comparison of the positions of the main and second resonances as determined from the transmission spectra and modeling of the spectroscopic ellipsometry data using the Lorentz oscillator model. The error bars are smaller than the markers and hence are not depicted in the figure. 
FIGURES

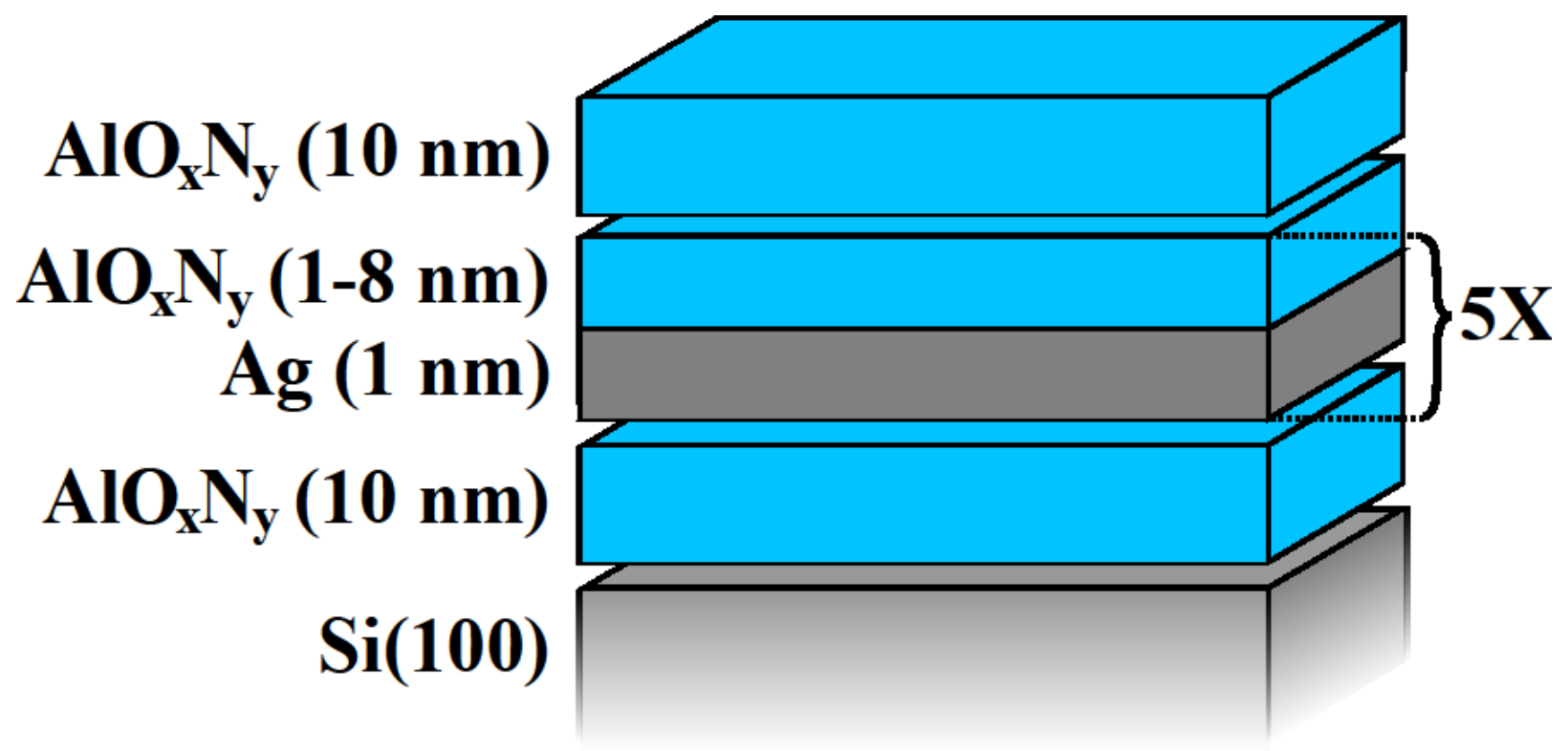

FIG. 1 

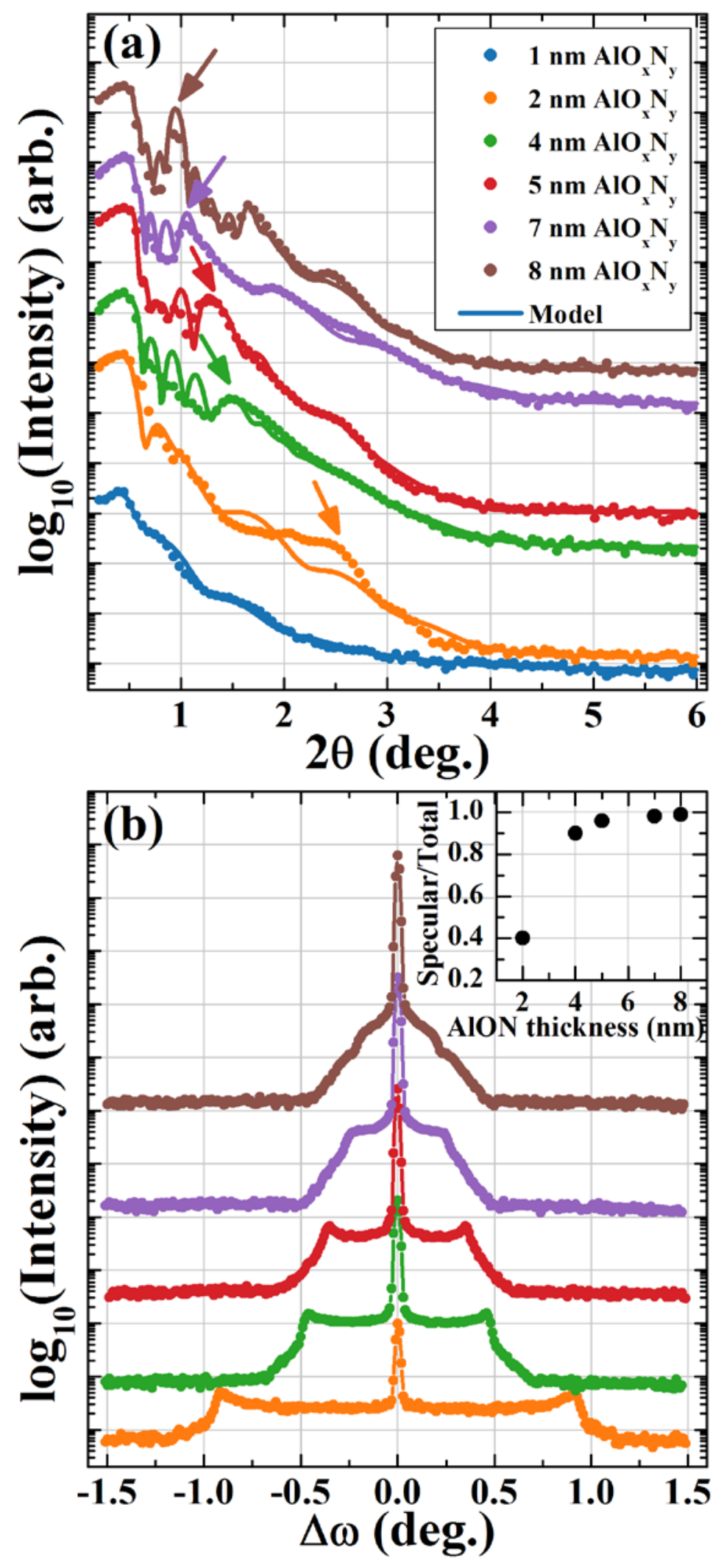

FIG. 2 


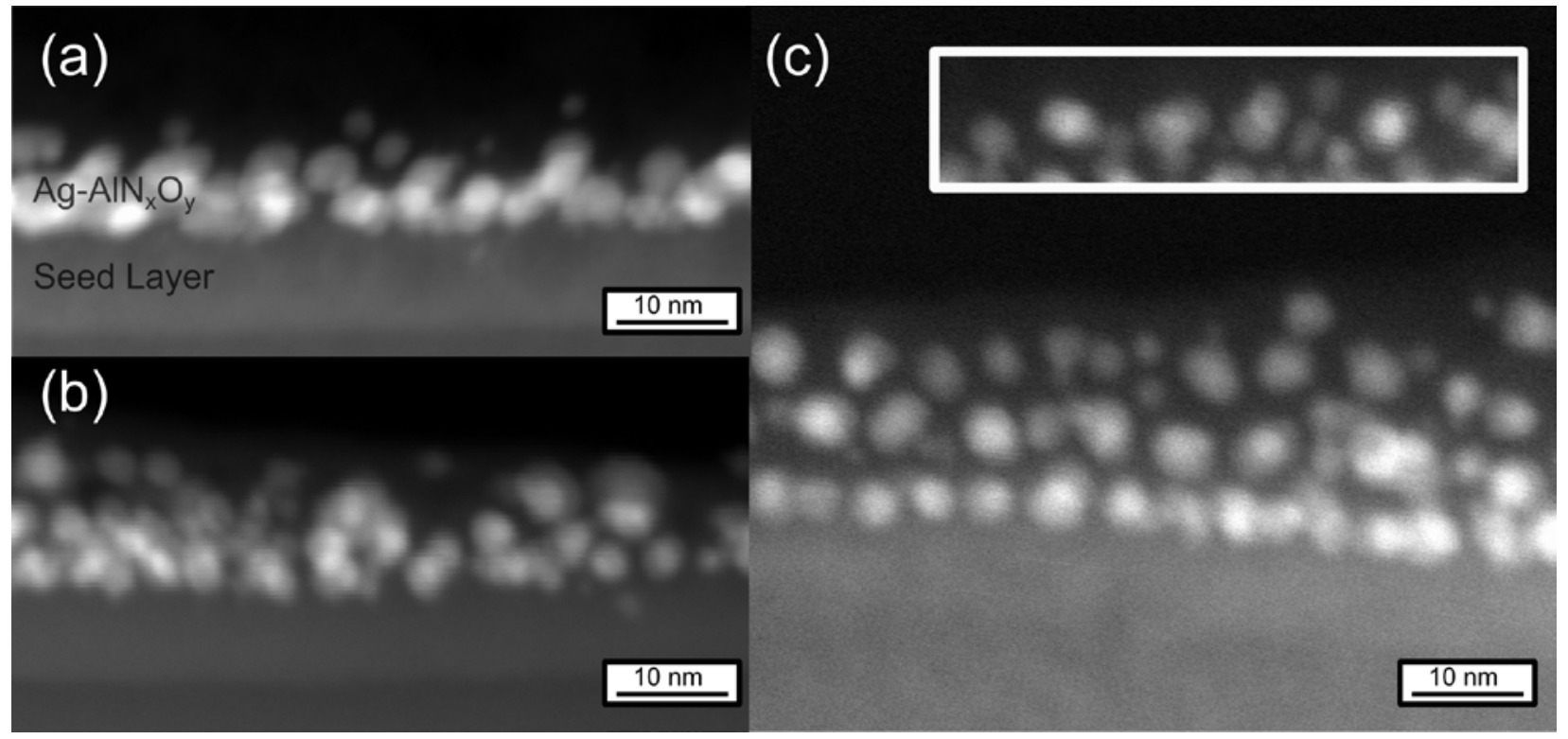

FIG. 3 


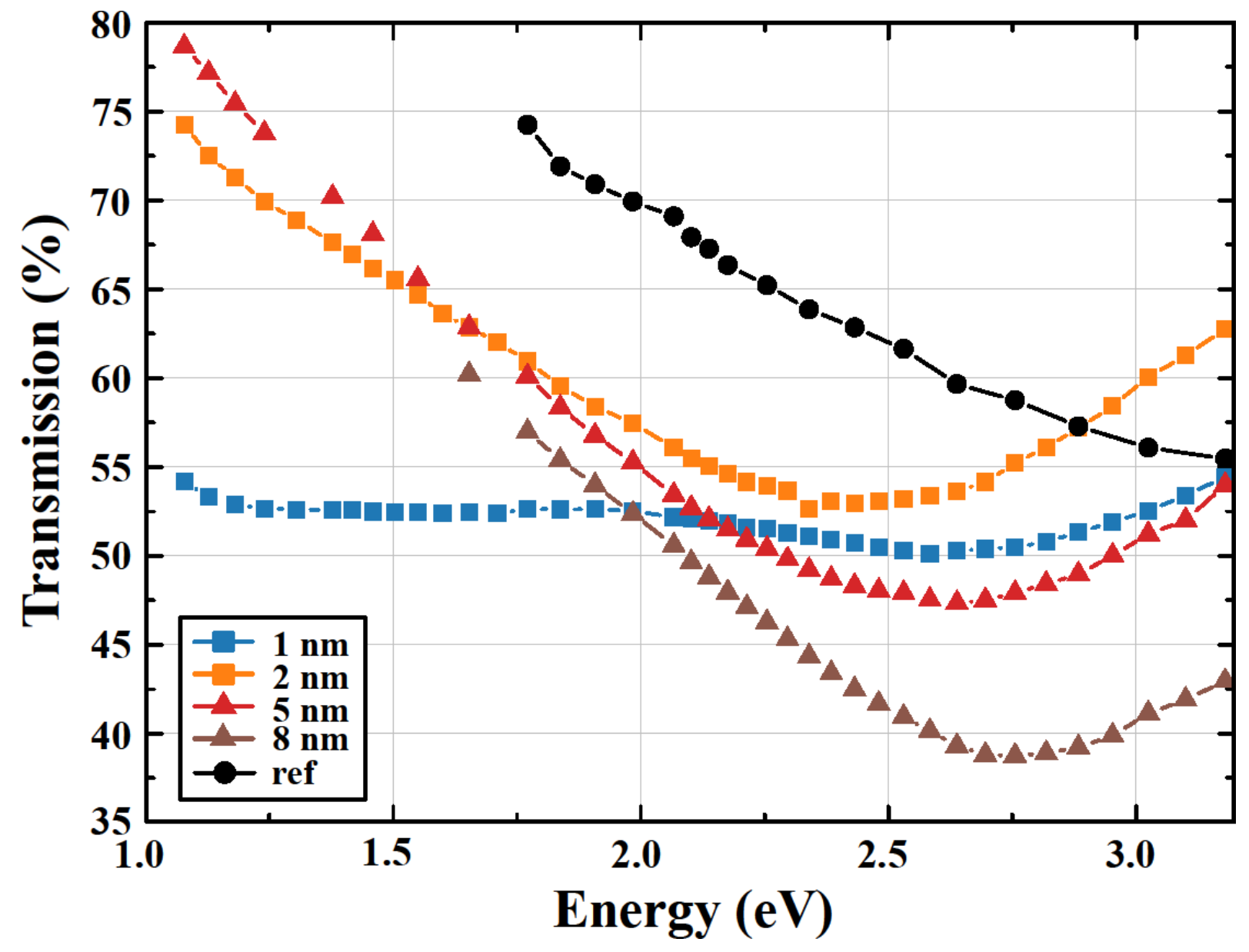

FIG. 4 


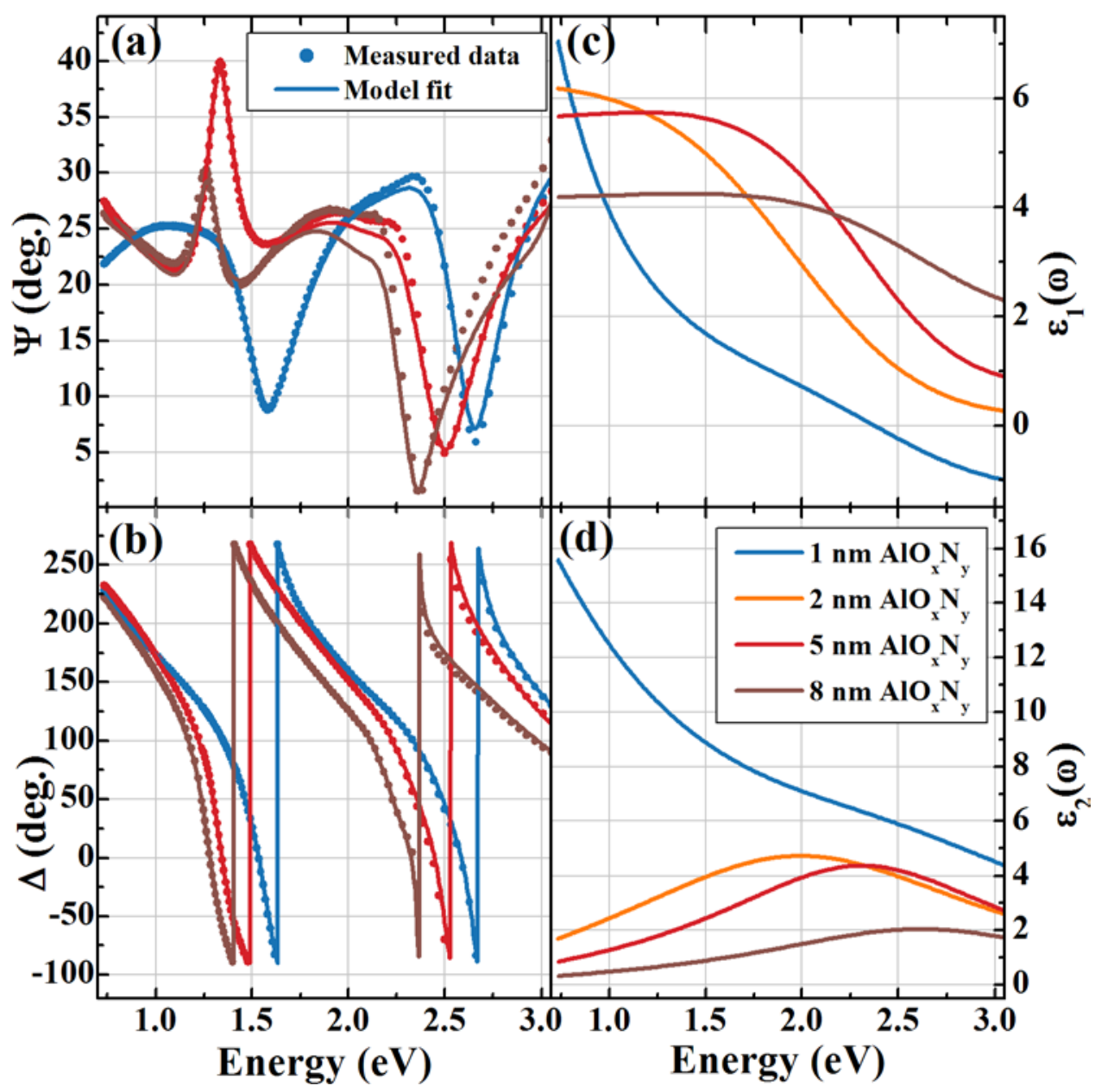

FIG. 5 


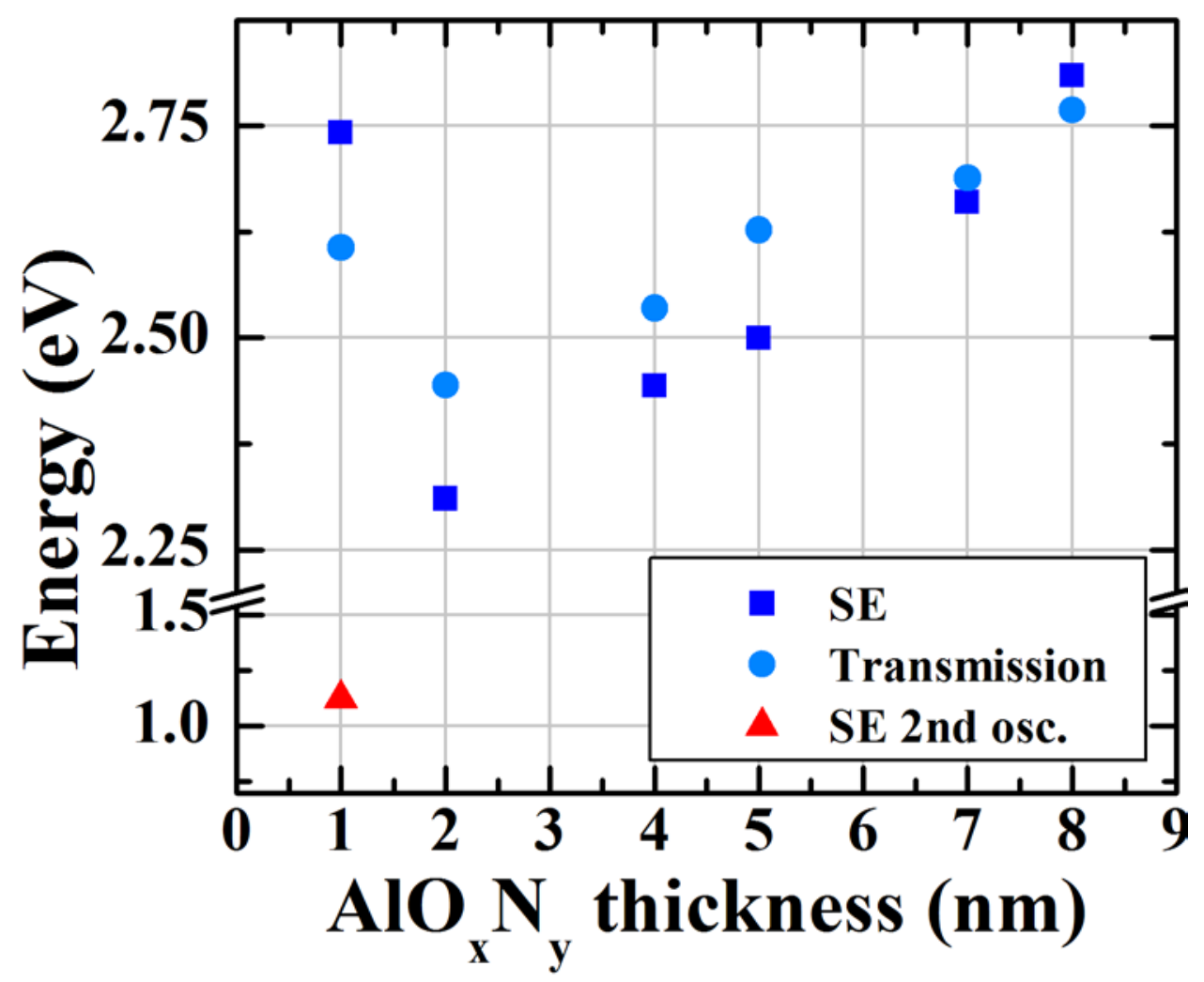

FIG. 6 
$\mathrm{AlO}_{\mathrm{x}} \mathrm{N}_{\mathrm{y}}(10 \mathrm{~nm})$

$\mathrm{AlO}_{\mathrm{x}} \mathrm{N}_{\mathrm{y}}(1-8 \mathrm{~nm})$

Ag (1 nm)

$\mathrm{AlO}_{\mathrm{x}} \mathrm{N}_{\mathrm{y}}(10 \mathrm{~nm})$

Si(100) 


\section{(a)}

(c)

$\mathrm{Ag}-\mathrm{AIN}_{\mathrm{x}} \mathrm{O}_{\mathrm{y}}$

Seed Layer

$10 \mathrm{~nm}$

(b) 


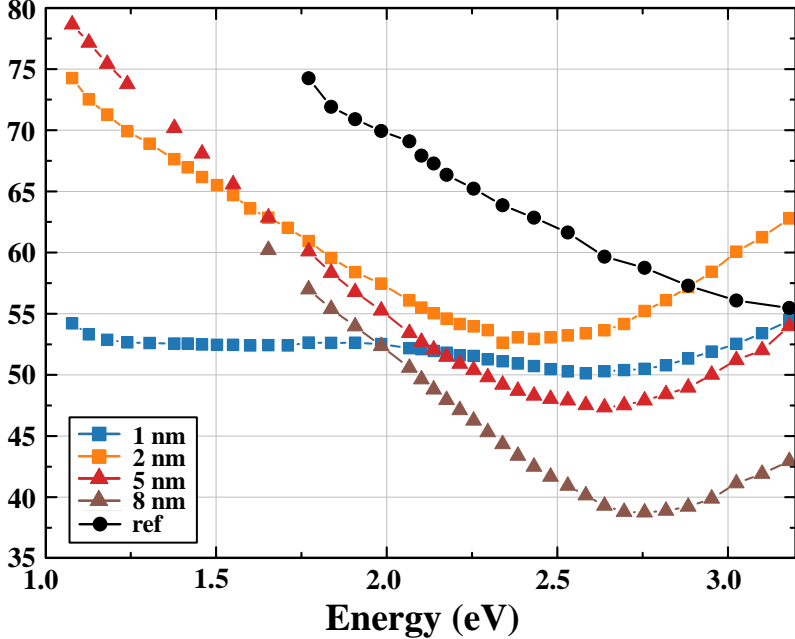




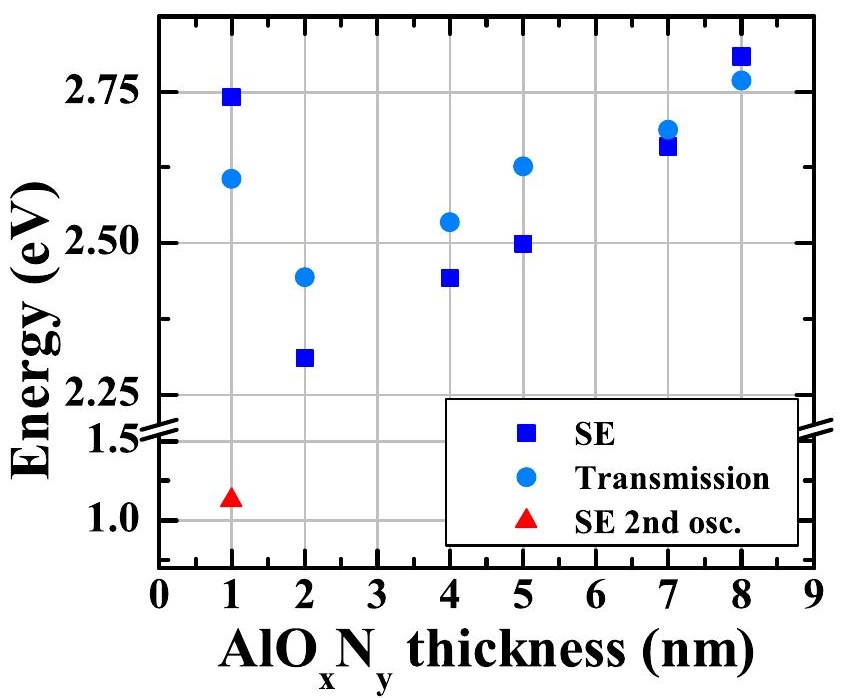




\section{Supplementary material:}

\section{Synthesis of tunable plasmoinc metal-ceramic nanocomposite thin films by temporally modulated sputtered fluxes}

D. Magnfält, E. Melander, R.D. Boyd, V. Kapaklis, and K. Sarakinos

\section{X-ray diffractometry}

Grazing incidence X-ray diffractometry data in the range $30-50^{\circ}$ is shown in Fig. S1. For all samples a very weak and broad feature can be seen around $38^{\circ}$ corresponding to the $\mathrm{Ag}(111)$ reflection.

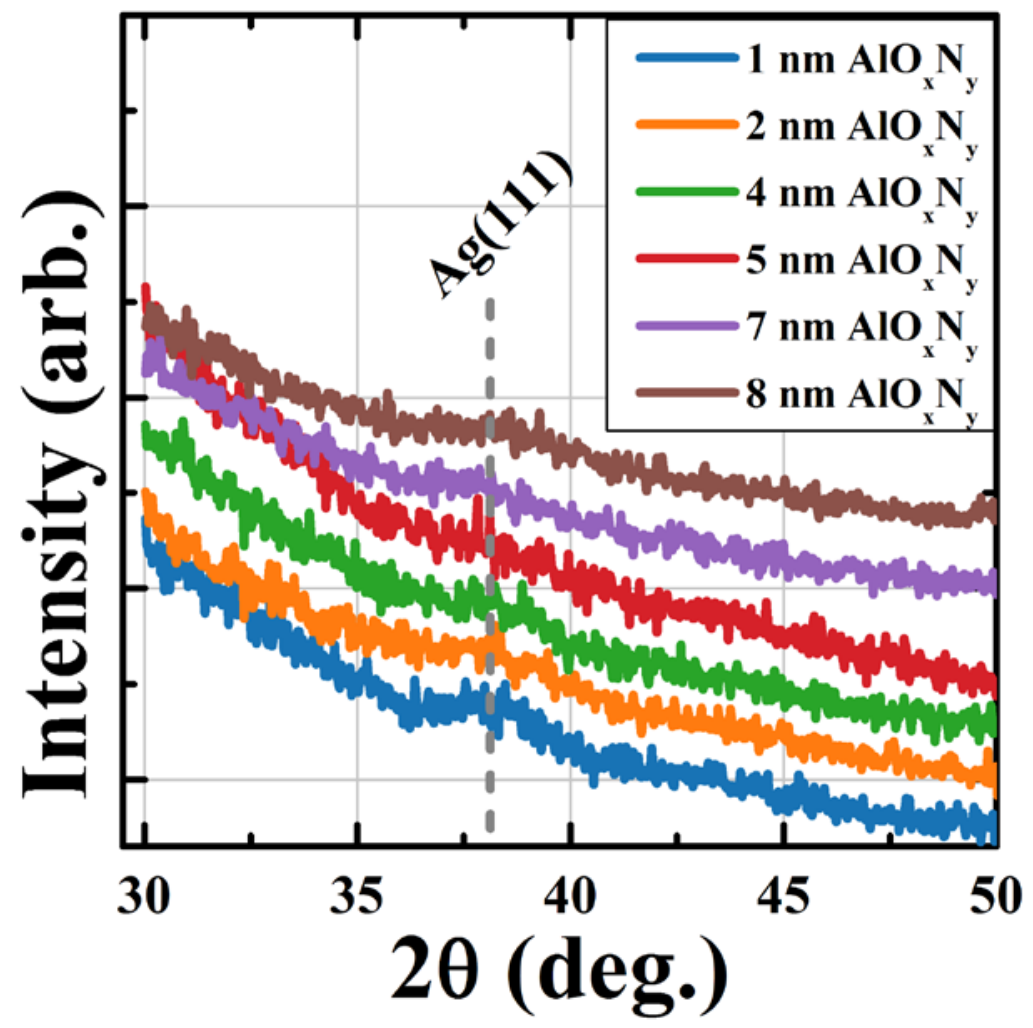

Figure S1. Grazing incidence $X$-ray diffractograms of $A g / A l O_{x} N_{y}$ nanocomposite films. The curves have been shifted horizontally for clarity. 


\section{Transmission electron microscopy}

HAADF-STEM images showing large area overviews are shown in Fig. S2. Comparing thin areas of the specimens, shown as darker due to mass-thickness contrast, with thicker areas, lighter, it can be seen that the film structure is similar across the samples. Overlapping Ag particles in the thicker regions of the samples give the impression of homogenous Ag layers. Some out-diffusion of Ag into the capping $\mathrm{AlO}_{\mathrm{x}} \mathrm{N}_{\mathrm{y}}$ layer, most likely an effect of TEM specimen preparation, can also be seen.

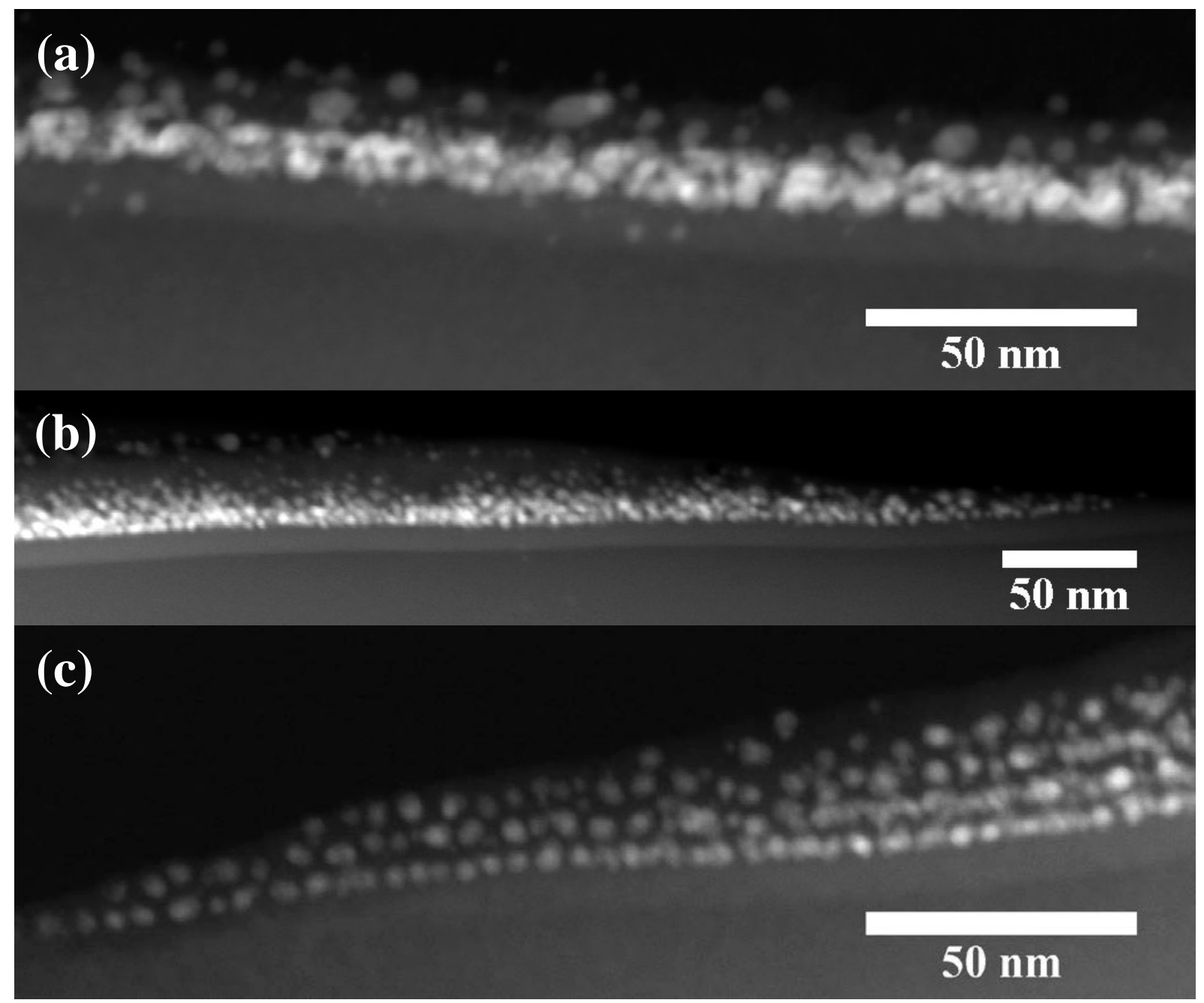

Figure S2. HAADF-STEM overview images showing the different layer morphologies for the samples with (a) $1 \mathrm{~nm}$ AlOxNy, (b) $2 \mathrm{~nm}$ AlOxNy and (c) $5 \mathrm{~nm}$ AlOxNy. 